\title{
Being There No Matter What: Working in Publicly Provided Homecare Services'
}

\section{Annika Vänje ${ }^{2}$}

Assoc. professor, Division for Ergonomics, Royal Institute of Technology (KTH), Sweden

\section{Karin Sjöberg Forssberg ${ }^{3}$}

Ph.lic, Division for Ergonomics, Royal Institute of Technology (KTH), Sweden

\begin{abstract}
The aim of this article is to critically explore how formal and informal work practices interplay with gender in the shaping of homecare service's work environments. An ethnomethodological view on doing gender is applied in combination with theories about challenges in relational work. The material is drawn from two projects represented by (i) a cooperative inquiry about Swedish homecare service's work environments, with homecare service workers and first-line mangers (seven included in this article) and (ii) six semi-structured interviews with employees from a national work environment authority. The analytic procedure was qualitatively based using an abductive approach when looking for cohesive themes. Gendered organizational shortcomings that interplayed with the shaping of the work environments were lack of clear work descriptions, boundaries for work, resources for embodied work, and limited knowledge about risk assessment in relational work.
\end{abstract}

\section{KEYWORDS}

Gender awareness / doing gender / emotional labor / homecare service work / work practices / work environment

\section{Introduction}

omecare service work can be described as low-status, nonprofessional, and not seen as contributing to societal production (Aronson \& Neysmith 1996; Keisu et al. 2016; Strandell 2020). Yet, at the same time, this kind of work is an essential part of the welfare state and plays an important role in countries such as Sweden, Denmark, and Norway, where the societies lean towards a model where the state takes care of the elderly (Kamp et al. 2013; Madsen 2018; Meldgaard Hansen 2016). The International Labour Organization (2016: pp. 22-23) advocates that reasons for the female domination in the service sector are that it offers domestic work and part-time jobs. Homecare service is one of these gender segregated jobs that for decades not just has been considered as low-qualified followed by low wages. Services such as cleaning private homes and shopping for people in need of care were performed earlier on by housewives in their 'spare time'. In the 1960s in Sweden, this non-paid work was transformed into paid work through the role of home helpers/visitors (Szebehely 2005). Even today in the Western

\footnotetext{
${ }^{1}$ You can find this text and its DOI at https://tidsskrift.dk/njwls/index.

${ }^{2}$ Corresponding author: Annika Vänje, E-mail: annivn@kth.se.

${ }^{3}$ Corresponding author: Karin Sjöberg Forssberg, E-mail: karinsf@kth.se.
} 
society, homecare service work is not considered an established and recognized profession, even though the job content is complex and many of the employees in this sector are trained assistant nurses. Strandell (2020) shows that in Sweden, homecare work consists of household tasks, administrative tasks, and social support as well as personal and medical care. In the same study, a comparison between the years 2005 and 2015 reveal that household tasks such as cleaning and shopping are less frequent in 2015, and that administrative and medical tasks as giving injections and participate in rehabilitation is more common in 2015 (Strandell 2020: Table 2, p. 142). On top of this, the same study pinpoints that the profession is more intense today and that work-related problems such as working short-staffed, lack of trust from management, weak collegial support, and mental exhaustion are more prominent in 2015 than in 2005 (Strandell 2020: Table 4, p. 144). In other words, homecare work has in recent years become more complex and intensive, which places new demands on the work environment and the organization. Yet, with the right kind of resources and support from the employers, this change can also pave the way for new professional roles and identities (Meldgaard Hansen 2016).

Further, publicly provided homecare service is a sector, which in the Western world has adopted New Public Management as a steering model (Brignall \& Modell 2000; Pollitt \& Dan 2011), which is influenced by industrial production concepts. The main driving forces for implementing this management approach were to create more efficient and profitable organizations (Pollitt \& Dan 2011). However, NPM includes management tools and key performance indicators that not necessarily take the complexity that care work comprises into account (Rosso \& Saurin 2018). In addition, a challenging task for the sector to fulfill, as the character of the work tasks are in many ways intangible and therefore difficult to estimate in hard values. On top of this, homecare service work builds upon expectations that women invest much of themselves in terms of effort and emotions in their caring practices, even if that is not necessarily rewarded ( Kmec \& Gorman 2010). This 'extra' caring competence is often seen and valued as naturally given embodied female trait (Purkis et al. 2011), and not as gained by educational training and professional experiences.

Given that mainstream research about work environments often are gender blind and seldom provide a gender critical analysis (Bolin \& Olofsdotter 2019; Vänje 2013), this article strives to contribute to this knowledge gap by providing an understanding of the ways in which gender is shaping female dominated work environments in publicly provided homecare services. The overall aim is to go beyond formal organizational structures and practices in order to create a deeper understanding of the concerned work environments. Two action-oriented research projects about publicly provided homecare service's work environments serve as cases. Together, these projects comprise voices from three municipalities, and a national work environment authority. More specifically, the aim is to explore organizational preconditions by identifying and critically examine formal and informal work practices and how these interplay with gender in the shaping of the work environments. An ethnomethodological view on gender and organizations serve as a theoretical framework, and the article is limited to discuss work practices and work environments from the point of view of homecare service workers and first-line managers as well as work environment specialists. The care recipients and their families' perceptions of homecare services are beyond the scope of this article. The concept work environment refers to the organizations' climate and culture. The concept organizational climate here represents how formal and informal work practices are perceived

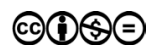


and performed by the organizations' members (Kines et al. 2011; Pousette et al. 2017). The concept organizational culture (Beer \& Nohria 2000; Gherardi 1994) is interpreted in terms of dimensions as local traditions, ethical values, and gender values.

\section{Background}

Gender equality is an important dimension when striving for a good work environment with possibilities to learn and develop the professional competence (Johansson \& Abrahamsson 2018). One reason to this is what we know from previous scholars that the meaning of gender has an impact on underlying power structures in work organizations (Acker 2009; Frisby et al. 2009; Olofsdotter \& Landén 2014). An ethnomethodological view on doing gender (Korvajärvi 1998; West \& Zimmerman 1987) helps to more easily see these often hidden practices that construct relations and hierarchization between individuals and groups in work organizations. These interactions often comprehend power-borne practices that can lead to nondemocratic social systems, and a mal-functioning organizational work environment (Frisby et al. 2009). The issue of power is not clearly on the agenda in mainstream research regarding work environments. However, we argue that being aware of gendered power structures and practices in an organization and in the context the workers face in their daily job is essential for being able to create a well-functioning work environment (Martin-Matthews \& Sims-Gould 2011). For instance, gendered values and power relations contributes to setting the social frames for how work tasks can and should be performed. In practice, a lack of awareness of the role of these power regimes (Acker 2006) in organizations can lead to a safety climate (Kines et al. 2011) that inherits different kinds of risky behavior, as these contexts do not themselves clearly provide or encourage space for questioning or making demands when the resources for doing the job are insufficient. Accordingly, social constructions of gender and power are important dimensions when investigating the work environment as they contribute to setting the underlying preconditions for not just how the work should be performed, but also for the organizational climate.

\section{The challenges of balancing professional and gendered requirements}

Since homecare service work consists of relational and practical work practices (Meagher et al. 2016), it can be understood as complex. Further, a blurry line often emerges between the homecare service worker's professional role and her or his personal emotional investments in the care recipients with whom they work. The concept emotional labor, established by the sociologist Hochschild (1990), is relevant when trying to understand how homecare service workers and first-line managers manage these kinds of complex emotional demands. As Hoschschild (1990) states these demands are not just complex they are also diffuse, and not only based on the work content itself but also gendered expectations of care. In practice, these implicit values around gender will influence how the homecare service worker manage different situations in the work environment. One such value is what Regnö (2013) in her research about female leaders in public care describes as not to whine about one's work conditions. On the contrary, the culture in these cases were to stay positive and not complain about lack of resources 
(Regnö 2013). In other words, emotional labor can consist of not just managing one's feelings in relational work, but also personal emotions and needs that arises due to work environment deficiencies.

Relational work consists in not only other words of subjective skills as emotional labor (Hochschild 1990), but also on the ability to handle those more or less invisible one-off cases that often arise in work with humans (Messing \& de Grosbois 2001). These invisible work practices can be said to underpin existing power structures and contributes to darken the complexities homecare service work comprises, as they are not brought into light and valued as formalized skills. Followed by the prevailing attitude in our society that these work practices do not necessarily call for vocational training, as they depend on the image of women as naturally gifted with the ability caring about (Husso \& Hirvonen 2012; Purkis et al. 2011).

It is not just the worker's emotions that are exposed in these jobs, the workers' physical body also constitutes a tool essential to the job of homecare service (Fine 2005). Examples of work practices when the body is used as a work tool are cleaning a home or helping the care recipient with personal hygiene. Even if the bodily closeness that arises in relation to the care recipients indirectly include the caregivers' mind and emotions into the work. England and Dyck (2011: p. 37) describe this angle of work as embodied day-to-day encounters, meaning that homecare service can be thought of as consisting of work practices that are more or less integrated into the body. Therefore, we can look upon the homecare service workers' work environment not only constituted through physical units in terms of private homes, meeting premises and transportation vehicles, but also the worker's body is a subject to being a 'platform' for work (England \& Dyck 2011). Meaning that the homecare service worker not just shifts workplaces and environments several times a day, but also perform work practices in spaces not necessarily designed for work (England \& Dyck 2011).

Further, private homes have become more common as work sites due to the last decades way of organizing care services for elderly (England \& Dyck 2011). This as hospitals and elderly homes have turned into specialist wards for only those with more severe medical needs, which is in line with the cost saving strategies that comes with NPM (Keisu et al. 2016; Strandell 2020). Followed by a situation where homecare services have to take care of not just more care recipients (Strandell 2020), but also more demanding ones. As Purkis et al. (2011) pinpointed earlier on, this was a shift not just from where the care work takes place, but also from not being incorporated within professional medical institutions (p. 91) and their regulations and policy work. The shift means that the welfare system is saving resources by letting less paid care workers do the job (Hallgrímsdóttir et al. 2008; Purkis et al. 2011) outside care wards and in premises not necessarily designed for professional work. Yet, this cost-saving strategy is a way to downward responsibilities (Hallgrímsdóttir et al. 2008) to an exposed group with limited power and resources (Hussein 2018).

\section{Overview of methodological approaches and data analysis}

As stated above, two different action oriented (Reason \& Bradbury 2001; Svensson 2002) research cases about public homecare services constitute the setting in this article. By using action-oriented approaches, we opened up for the possibility to gain deeper understanding of the concerned work environments and the doing of work practices (Gherardi 
2015). This as action research is about doing research with and not on organizations and practitioners, is based on core values as democracy and knowledge sharing on equal terms as well as joint critical reflections between practitioners and researchers (Aagaard Nielsen \& Svensson 2006; Reitz 2017). Further, using a feministic approach in actionoriented research helps us to see ongoing power dynamics and inequality regimes (Frisby et al. 2009; Maguire 2006) in work organizations. The first case consists of a cooperative inquiry (Heron \& Reason 2001) conducted within the frame of a larger research study about branch-specific work environment knowledge. This project ran for three years (2013-2016) and included three municipalities' homecare services as well as their occupational health care service (OHS) provider. However, in this article we only focus on data drawn from the actors in the municipalities. The second case is part of an ongoing larger action research study (2017-2020) where one part is about creating gender awareness in publicly provided homecare service organizations. Participating partner organizations are two municipalities and the Swedish Work Environment Authority (SWEA). For this article, we have used data from semi-structured interviews conducted in order to create an empirical basis for learning activities concerning gender within SWEA's organization. The action-oriented parts of these two projects are not in the scope of this article.

\section{Cooperative inquiry as a tool for data collection}

Participating actors that are included in this study were homecare service workers (four women), which also were appointed by the local union as safety representatives and their first-line managers (three women). They were all informed about the aim with the project that participation was voluntarily and that the gathered data would be treated confidentially. In order to keep the promised anonymity, it is only the inquiry participants' professions and gender that are stated in the result section.

Different methodological approaches such as self-reflections, joint reflections, that served as in-built validation processes, and input from research were applied during the inquiry's four cyclic phases: (i) identification of the inquiry's theme and form, (ii) selfreflections, (iii) learning and knowledge dissemination, and (iv) actions taken in the field (Heron \& Reason 2001). The jointly agreed upon topics to investigate further and more specifically within the scope of the inquiry concerned the daily work in relation to organizational preconditions for deliver quality care and service, as well as interactions with the occupational health service provider concerning work environment issues. External input to the inquiry consisted of tutorials given by invited researchers as well as the participating actors reporting of self-reflections from between the meetings. The inquiry ran for 1 year and included five 3-hour meetings. The first four meetings were audio recorded and fully transcribed by a firm procured by the university. Reflections made on paper posters and white boards (documented by mobile phone photos) complemented the transcribed material.

\section{Interviews}

The semi-structured interviews (Kvale \& Brinkmann 2009) were conducted with six (three women and three men) work environment inspectors employed at the national 
work environment authority. Together, they represent experiences from working with inspections in the two focus areas: (i) public care and homecare services and (ii) systematic work environment management in gender-segregated organizations. However, only statements regarding homecare services are used in this article. The informants were selected based on partly having experiences from inspecting gender-segregated work areas, partly from actively participating in a dialogue seminar (Gustavsen 1992) that was conducted at the authority and within the frame of the research project. The interviews lasted for approximately an hour and had their departure in understanding their professional role as inspectors, identifying what kinds of work environment issues they find challenging and if and how they include a gender perspective in their inspections. All interviews, except one, were audio recorded and fully transcribed. The informants were informed beforehand about the project and the interviews, as well as about their right and ability to refuse participation.

\section{Analytic process}

The first step of analytic processing of the data from the inquiry was built into the methodological approach of co-operative inquiry and performed on scene during the inquiry meetings through joint validation of the researchers' interpretations. In order to move from this local praxis-based knowledge to more general knowledge (Toulmin \& Gustavsen 1996), a more traditional approach was undertaken. Thematic-based (Braun \& Clarke 2006; Clarke \& Braun 2018) analysis was performed, with the aim of identifying common patterns and recurring statements taken by the homecare service workers/safety representatives (named homecare service worker in the text that follows) and the first-line managers. Four different patterns were identified through a coding process, (i) organizational work environment, (ii) time, (iii) technical tools, and (iv) physical demands and unforeseen events. These were condensed one step further through reading the coded material and searching for likenesses between the four cohesive themes. Thus, family resemblances (Nyström 2005) were identified, and two overarching streams emerged. These are presented in the Result section.

The semi-structured interviews conducted in the second project were also thematically analyzed (Braun \& Clarke 2006) on an empirical basis, but this time by using NVivo software package 12 Pro. A template based on recurring themes was created in the software program and after reading through the whole material. Quotes were then coded into the identified themes, a process which gave them a content. Then the themes were condensed one step further, this time by hand and by carefully reading through the content of the created template. This process resulted in three overarching streams, which are presented in the Results section.

\section{Results}

This section presents the results from the cooperative inquiry and the semi-structured interviews with the work environment inspectors. The text is structured according to the identified overarching streams. Two of them represents the content from the inquiry, namely (i) work environment risks in relational work and (ii) the interplay between 
physical demands, emotional demands, and organizational preconditions. Three of them represents the content in the interviews, namely; (i) gender-related differences in work environment inspections, (ii) gender awareness and the inspected workplaces, and (iii) organizational work environment issues.

\section{Voices from the municipalities}

The empirical findings from the inquiry that give meaning to the two overarching streams, namely (i) work environment risks in relational work and (ii) the interplay between physical demands, emotional demands, and organizational preconditions, are presented in the following two sections together with quotations by the homecare service workers and first-line managers.

\section{Work environment risks in relational work}

The participating first-line managers and the homecare service workers highlighted to a great extent issues that concerned the organizational work environment. Above all, the discussions were about work hours and time schedules. The time schedules were perceived as very tight and did not allow for the kinds of unforeseen incidents that so often occur in relational work.

Then a woman from X-town calls and says that a woman has activated her alarm. Her lock doesn't work. They have keyless doors. She cannot lock the door from inside. ... I had several double shifts and I was there for forty minutes ... I stood there, it was really not my problem. But, I had to solve it. And we do this over and over. (Homecare service worker; woman)

The procedure of counting work time was based on a plus and minus system, and the clock started to tick inexorably when the working day should start. This means that in practice the care workers had little control over their time, and if they were delayed, for example due to staffing issues in the morning, they started the day with a minus. The time system itself demanded detailed management, something that was difficult for the first-line managers to address, as they knew very well that the job was more complex than separate single time units were. This was a clear example of how the first-line managers tried to balance between the management system's rationalities and their workers' professional needs.

... today we shall work according to taken decisions, like these certain tasks should take seven minutes, that is how we are supposed to work, you are not allowed to do the stuff you used to do ... And, how am I supposed to get a person, who just want to do good, on other thoughts, she will not feel satisfied by the end of the day. (First-line manager; woman)

The first-line managers perceived it as hard to get more experienced workers to set limits in their relational work by changing their work practices. Moreover, a throttle for 
mentally demanding work situations was absent, meaning that negative thoughts about work were easily spread and infected ordinary work meetings. This can be interpreted as a result of not valuing care and domestic work task for its complexity, which indirectly leads to lack of and poorly adjusted resources.

And, I think you don't have time to talk about anything else but the daily work, even in coffee breaks and lunches ... There are so many problems to solve ... (Safety representative, woman)

It was of concern that the high rates of sick absences meant that those in full-time employment had to manage more of the more difficult care recipients than usual, in terms of being in need of medical care, having dementia or being abusers. The latter resulted in a situation that increased the risks for different kinds of harassments, threats and violence. Accordingly, in some situations, two care workers were needed in the care recipients' homes. However, nearly no time was allocated for shared visits in the work system.

Yeah, you need to get the whole picture, sometimes you need to be two that do the cleaning. But, we are supposed to be very quick and not accept help from one another. (Homecare service worker; woman)

Among the first-line managers, this feeling of powerlessness was articulated in terms of that their businesses did not produce anything, and therefore, they had limited resources. Accordingly, they did see how the gendered norm in our society around care work was mirrored into informal organizational values and the municipalities steering model.

I mean, we are just seen as a cost for the municipality; we do not generate any profit.

(First-line manager; woman)

One main theme during the inquiry meetings was that of unforeseen incidents. There were tight time schedules and no guidelines for how to act when unforeseen events occurred, which affected both the workers and the first-line managers. Consequently, it turned out that in many situations it became the individual's responsibility to take the required action. This was a clear example on how scarce resources in combination with unclear work descriptions generated emotional burdens and individually based work practices, instead of working according to common organizational and professional values.

As a manager, I also take responsibility during weekends. Even if I am not on duty.

(First-line manager; woman)

It was mentioned in the inquiry that the municipalities had checklists for risk assessment, but that they were seldom used. A formalized safety round or risk assessment could mean refurnishing a home to improve the physical work environment or the identification of needed lift tools to make the job less physically demanding. However, these rounds did not include assessments of the emotional labor. Accordingly, incident 
reporting was neither adjusted to those kinds of work practices that constitutes relational work nor used for improvements of the social and organizational work environment. Resulting in a vicious circle of doing work practices that was neither valued for its complexity nor included in the formalized work descriptions.

\section{The interplay between physical demands, emotional demands, and organizational preconditions}

The managers highlighted differences between junior staff and the more experienced staff. They perceived that the older homecare service workers had a deeper and more emotional approach to the care recipients than their younger colleagues. The younger individuals' more rational approach to the job was perceived as not being committed, despite the fact that it was in line with the existing management system to be efficient. This can be explained as a result of that the NPM-inspired steering model was not, by the managers and the more experienced staff, seen as opening up for those kind of work practices that open up for deeper values. However, it can also be interpreted as a perception of that the younger homecare service workers did not follow the gendered norm when it came to how to provide care and services.

Nevertheless, I think many of us have been affected by this system. They don't like close relationships. They want to cut themselves off a bit. Swoosh in and out, that suits them in some cases too. (First-line manager; woman)

There was an awareness of the interaction between physical and organizational demands and how they could affect one's health. This can be described as a perceived blurriness between the body used as a physical tool and emotional investments in the job and in the care recipients, where the body was also an important element. Again, we can see how the lack of formal structures for the work and informal work practices not only forces an individual responsibility but also contributes to hiding care work's complexity and prevailing power structures.

I believe that it is not just that it is physically demanding; it is also socially demanding, that is why you do not have the effort, mentally I mean. (Homecare service worker; woman)

However, it is not sure that the demands are physical or mental. I am on the go all the time to different places ... Then, it depends on the consumer how troublesome that person is. (Homecare service worker; woman)

When discussing motivators for being at work, the homecare service workers came up with only two factors, namely, (i) to be there for a care recipient that needs you and (ii) having an independent job. On the other hand, motivators desired by the care workers were more numerous and included, for example, greater participation in planning processes and having support available to counteract mental and physical overloads.

The results above pinpoint a gendered norm where inequality regimes in terms of poorly adjusted resources, lack of formal structures, and understanding of the nature of the work as well as no structures for participation interplays in the shaping of the work environment. 
The inquiry itself had built-in power dynamics between the first-line managers and the homecare service workers. We knew on beforehand that having representatives from two different organizational levels in the same room would mean disagreements on some issues. The starting point was that it is in these dynamics of contradictions that in-depth knowledge can arise, if they are managed in a reliable and secure way for the participating actors. In this case, the first-line managers tended to take interpretative prerogative in the joint discussions that were supposed to be on equal terms. For us as researchers, the feministic-inspired research approach entailed possibilities to identify and manage these unequal power relations in the moment. Examples on actions taken are the choice to split workers and managers into different work groups and that the university researchers had to in a clear way make space for the workers in the joint discussions.

\section{Voices from the inspecting work environment authority}

The thematic analysis of the interviews with the national work environment authority's representatives resulted in, as stated above, three overarching streams: (i) gender-related differences in work environment inspections, (ii) gender awareness and the inspected workplaces, and (iii) organizational work environment issues. These three themes constitute the structure in this section.

\section{Gender-related differences in work environment inspections}

Half of the interviewed inspectors have performed around 30 inspections each within elderly care, where public homecare service is an essential part. Mostly they undertake these inspections alone, but can go in pairs in the beginning of a project in order to secure that they examine in a similar manner when they do workplace visits. After each inspection, they write an inspection notification that nearly always includes measures to be taken by the concerned employer, which is then communicated to the employer in a feedback meeting.

The inspectors convey that there are differences in how female- and male-dominated workplaces are inspected. In male-dominated work areas, the authority is much more forward in both how the inspections are presented to the employers and how they are conducted.

... our inspection that we do in schools and in care, they are like ... that you send a notice about your arrival and that we are going to look at these things, and we will be there in three weeks, keep in touch if that is not convenient so we can find a new time ... those who inspect the construction sites, they are more like now we have some men here who have taken photos and this will cost you some money. This takes like 28 minutes, and then they continue to the next site. (Inspector; man)

The differences in inspections of gender-segregated work environments are according to the interviews because it is much easier to place demands on obvious risks that are tangible or hazardous for the worker in the moment. That is, risks are demarcated with more ease when an inspector can clearly see a connection between the risk, its implications, 
and what the current legal framework says. Meaning that emotional burdens and stressful situations in homecare service work are not obviously assessed as work environment deficiencies (Messing \& de Grosbois 2001), as a result of that the inspectors find it difficult to identify such kinds of indirect risks. However, the inspectors who also served as managers were aware of this gendered work culture which resulted in that they actually did not take SWEA's provisions into account.

... it could be a pressure vessel that explodes ... And that will generate effects, but all these people who are torn by bad working conditions, slowly, slowly ... it is not risky in any way. (Inspector; man)

... then I anchored, and the project team, I think very well in conveying the message to the inspectors that, well, that is, we make demands based on our law and legislation, whether it is female-coded or male-coded activities. (Inspector; woman)

Further, it was mentioned that it is simpler to apply a gender perspective when you inspect a whole organization, than if you just visit a workplace and do not take the systematic work environment management into account, or how it is implemented into all organizational levels. It was also perceived as difficult to inspect gender-segregated work environments, as they find it hard to pinpoint gender equality issues in an environment that is homogenous with a strong prevailing norm. These are statements that visualize how hard it is for employees to see the implications of the prevailing gender norm, when the meaning of gender is clearly manifested in the work culture (Gherardi 1994). Additionally, the inspectors perceived it as hard to reflect on gender issues. Especially without being stuck in more biological and natural explanations to differences between the sexes. In the long run, this shows inspectors' need for deeper learning about organizational work environment and the meaning of gender in different work contexts.

I find it difficult ... to talk about it when you're in ... in organizations where only women are so to speak. In order to (sigh) ... there you also easily get stuck in this with the attitude that women and men are different and such ... (Inspector; man)

\section{Gender awareness and the inspected workplaces}

Gender equality is understood in different ways by the inspectors. However, there is a common awareness that women are more often on sick absences than men, and that the vast majority of registered work-related diseases concern women. There is also a difference in which kinds of diseases that are reported, where mental illnesses are more common in female-dominated workplaces as homecare service work. Despite the perceived difficulties in how to risk assess organizational and social aspects in relational work, there is an understanding of that women are more exposed to risks that generates mental illnesses.

Women's sickness rate and ... We also point out that what has been reported to us, that it is women that are more frequent than men are and that what you report is (sighs) what is linked to organizational and social work environment. (Inspector; man) 
Accordingly, the inspectors struggle with how to introduce a discussion about gender equality during inspections. One way to do this was by raising the issue of the necessary conditions for doing the job: should it be so demanding that an average person is not fit enough to undertake? Another option was to discuss why women and men are engaged in different work tasks. More specifically, when inspecting homecare services in the municipalities, the experiences are that there is still a very large difference in resources, in comparison with male-dominated technical jobs. This confirms the results from the inquiry and how the employees in homecare services struggle to cope with scarce resources due to gendered expectations on what relational work demands.

In discussions about gender equality, they (Homecare service workers, author's comment) talk about themselves when describing it is difference in access to work equipment, ie cars, clothes, premises and so on. Moreover, the time aspect. Because as they say, yes, "but the men they have time to go there, and they can go several workers to one place ... while we may have to drive each other around in one car". (Inspector; woman)

Identified work environment deficiencies in homecare services are often related to a lack of work descriptions on how to perform certain tasks. Examples include lack of formalized routines for how work clothing (if there are any) should be taken care of, lack of instructions for how to clean private homes as well as professional cleaning tools. The culture in the female-dominated work units is characterized by loyalty and not questioning different issues (Regnö 2013), for example, the tight time scheduling or access to decent transportation between the care recipients. The latter is an important issue as travelling between the care recipients constitutes a vital part of the workday. Accordingly, the homecare service workers' workplaces can be said to consist of the municipality's premises, the care recipients' private homes, and where the transports take place.

To not demand needed resources can be mirrored against the perceived powerlessness that was identified in the inquiry (Acker 2006). A dilemma, which easily constitutes a negative spiral that needs to be broken as it in itself, is a hindrance for work environment improvements and allocation of adjusted resources (Olofsdotter \& Landén 2014).

... this with cleaning and so, it has been like in some way you as a worker are not questioning (lack of conditions, author's comment) either, there is such a strong gender perspective in it. (Inspector; woman)

Work clothing is a prominent work environment issue in different ways for the homecare services. This is because there is often a lack of resources to purchase proper clothing according to existing regulations, but also because there are often unclear or no routines for how such clothing should be taken care of.

You (as a manager, authors comment) simply cannot say you don't have money left, clothes should be there and then you have to push that issue ... otherwise, they have as much clothing as possible in technical maintenance and on the public ferries ... but within the homecare service, it is very tight. (Inspector; woman) 


\section{Organizational work environment issues}

The different kinds of emotional burdens that were identified by the first-line managers and the homecare service workers in the inquiry were also noted by the inspectors during their workplace visits. The inspectors talked about these burdens as unidentified work environment risks that caused different stress reactions among the staff. Accordingly, the inspectors framed these unidentified risks as neither being reported formally as incidents nor investigated by the municipalities. The lack of systems for incident reporting was seen as one of the most prominent work environment deficiencies in homecare service.

You have to do incident reporting, in all aspects, not only record slipping and getting injuries, but ... risk assessments in general, thus documenting risk assessments of the risks you actually have. (Inspector; man)

The issue of boundless work within homecare services has been on the agenda of the work environment inspectors. Their experiences are that it is often difficult for the care workers to set boundaries at work. A difficulty that is compounded by unclear job descriptions for both bodily and emotional tasks in the care recipients' homes.

It is quite often that we encounter that you choose ... the person in favor of one's own work environment. In everything from physical workload issues to the organization of working hours. (Inspector; man)

Along with unclear job descriptions and invisible work tasks comes difficulties to conduct incident reporting of different kinds of accidents that occur due to deficiencies in the organizational work environment.

Surely, there should be plenty of incidents, but it doesn't. ... There is a tradition about the physical, there is a tradition of working with slipping, squeezing, falling, machines and such things, and you have been working with ergonomics for quite a long time ... What comes with being sick today, which is more connected to that ... you end up in frustration because you see that you would like to do more than you can and ... (Inspector; man)

... It is unspoken tasks, that you do not really identify it ... as a job. Thinking my own analysis is also, why you do not see it as a job, because it has been there for many years. (Inspector; woman)

\section{Discussion - organizational preconditions and individual work practices}

Even if the second most common identified risk factor in the EU-28 member states in 2019 was having to deal with difficult patients, pupils or customers (EU-OSHA 2019), it is still difficult in practice to identify and manage constant emotional burdens or oneoff cases as work environment risks. We argue that one reason for these deficiencies is a blind spot within work environment management, namely understanding the meaning 
of gender. Our results show that there is often a binary view of gender in the studied contexts, where women are perceived and treated as a homogenous group (Armstrong \& Messing 2014). This more static view on gender not only consolidates the gender order, but also obscures power structures in the work environment. However, if we instead look at gender as consisting of different femininities and masculinities (Budgeon 2014; Jenkins \& Finneman 2018), constructed through the interaction between organizational structures, work practices and intersections (Simpson et al. 2016) such as social class, education, and working conditions, we gain the possibility of a deeper understanding of the shaping of the local work environment.

The lack of structures for how to perform work tasks renders the organization's informal culture and climate (Gherardi 1994; McCann et al. 2015; Pousette et al. 2017) strong determinants for how the work should be done. In both presented projects, this generated informal practices that were explained on the basis of care workers' own wish of how to perform work tasks. The inspectors also raised the example of the lack of instructions for how to do the cleaning, or the lack of professional cleaning equipment as a result of an informal work culture. However, these are individual practices that support the existing traditional gender order (Hirdman 1988), and the view of women as a homogenous group (Armstrong \& Messing 2014). Further, to not make these personal investments would on an individual level be to breach what is expected of you as a woman (Husso \& Hirvonen 2012) when performing relational work. The first-line managers and the inspectors also articulated that it was hard to tell the more experienced female workers to eliminate some of the relational work. These are different examples of how the power structures that operate around gender (Budgeon 2014; Olofsdotter \& Landén 2014) as well as the intersection of social class affect the work environment.

Further, the lack of strategies and processes for handling unforeseen events or invisible practices can be seen as a platform for what Aronson and Neysmith (1996) call a blurring of the homecare service workers' professional and private self. There is, in this sense, a grey zone consisting of formalized and institutionalized work tasks and work tasks that are hidden but expected to be performed (Kosny \& MacEachen 2010; Messing \& de Grosbois 2001). This places the homecare service worker in a situation in which she or he must, on an individual level, decide where the line is to be drawn between the professional I and the private I (Hochschild 2003). The first-line managers expressed this uncertainty, or blurriness, through the perceived need to be always reachable, even outside their paid work hours.

If we look at the dimension of doing gender (Acker 1990; Kvande 2003; West \& Zimmerman 1987) in relation to the results from this study, we can illuminate different kinds of actions that interact with each other and shapes the work environment. The doing gender dimension that concerns self-definition (Acker 1990; Vänje 2005) can be said to be the most profound one. If we summarize the results through this lens of the self, we end up with interpretations of pride for being needed by the care/service taker but, at the same time, no platforms or arenas for the transfer of professional experiences and learning from each other. This fact led to a sense of working for oneself and not a sense of coherence (Antonovsky 1990). The constructions of femininity were accordingly intertwined into the work environment through actions as not complaining or making demands (Regnö 2013) when resources are insufficient for doing the job properly, but also indirectly through values about gender in the society as well as the work environment inspector's perceived difficulties in identify gender related issues when visiting workplaces. 
Not mentioned in either of the projects was being a skilled professional, which in itself can be added to the list of practices that maintains the prevailing gender order whereby women work in care due to a natural talent (Purkis et al. 2011) for helping others, rather than entering a complex profession. These deficiencies are in themselves signals of inequality regimes (Acker 2006; Szebehely 2005) within the organization. This is due to the fact that if a job is not valued as a profession and the work includes non-formalized tasks done by low-educated women then there is an inequality regime (Acker 2006), which through these uneven power structures indirectly constitutes work environment risks (Messing 1998). Such situations were frequent according to the work environment inspectors, based on the fact that incidents were seldom identified or registered.

The construction of the body as a work tool (England \& Dyck 2011) can be described as multidimensional, where the body is partly used for physical practices such as doing house cleaning and partly used as a tool for helping with caring that could entail close body contact (Martin-Matthews \& Sims-Gould 2011). Another way of describing this multidimensional phenomenon is by using England's and Dyck's (2011) interpretation of the concept embodied in the practical example of the wish to be there for the care recipient. Our interpretation of this 'being there' is that it involves both physical and emotional presence, or an example of when the relational work is embodied in the care worker's physical body and mind (Fine 2005).

The construction of the workplace in homecare services can at first sight seem to regard only the care recipients' physical homes. On the other hand, our results are in line with scholars such as Armstrong and Messing (2014) as well as England and Dyck (2011) who argue that the workplace in homecare service is of a more complex nature, and should therefore not be reduced to one single setting. Through the inquiry we understood that the workplace consisted of private homes, common meeting premises as well as where the traveling between care recipients takes place. The latter can be a car, a bicycle, on foot or public transportation. The inspectors confirmed this interpretation by raising the deficiency whereby municipalities did not include where and how travel is undertaken as a given workplace issue, despite the fact that in homecare services traveling between care recipients is something which is done several times a day. However, this traveling is, as the findings here show, often overlooked and therefore becomes what Messing and de Grosbois (2001) calls a neither recognized nor visualized workplace issue.

The work environment inspections play an important function when it comes to what kinds of work environment issues are brought to light, both during the visits and afterwards as well as for future research. Accordingly, the inspectors' knowledge about gender, homecare services' work environments and workplaces are crucial for being able to identify and counteract risks in a systematic way. However, the methods for doing work environment inspections are colored by gendered values resulting in different approaches depending on context, followed by the fact that more subtle and indirect risks as emotional labor are not made visible. This can be described as a signal of lack of gender awareness (Däldehög 2012) among the inspectors and in the authority's organization. One example is when risks are defined based on the type of deficiencies that arise in the male-dominated technical sector, which often are more direct and possible to see with the naked eye. Further, the different ways of conducting work environment inspections mirror in themselves that social constructions of gender are not challenged 
(Ringblom 2019), but rather reproduced both in the local organizational context and on a national inspecting level.

\section{Conclusions}

In this article, we illuminate how gender contributes to shape the work environments in public homecare services in different ways. More specifically, gendered values are present in the daily work and closely intertwined with the homecare service workers' self-definitions, as well as through external gendered expectations and values around care and service work. This is expressed through an organizational culture where emotional labor is often performed outside formalized work tasks and in a context where it is not self-evident to make demands. In turn, this leads to that emotional labor is neither visualized nor valued as work environment risks. Lack of clear work descriptions and resources not adjusted to the work demands underpins in itself the prevailing power structures, and rather strengthens than deconstruct traditional gender values and women's social subordination in these contexts.

The presented results indicate that (i) lack of clear work descriptions, (ii) lack of clear boundaries for work as well as lack of adjusted resources for embodied work, and (iii) limited knowledge of how to identify work environment risks in relational oriented work interacted in the shaping of the work environment and the doing of gender.

Inequality regimes and the lack of risk assessments of emotional labor could be counteracted by developing gender awareness on individual as well as organizational levels in public homecare services. Further, research about development of gender aware work environment inspections would contribute to challenge the prevailing gender order in this sector.

\section{Acknowledgements}

We are grateful to AFA Insurance in Sweden for funding the two research projects presented in this article, without which present studies could not have been completed.

\section{References}

Aagaard Nielsen K. and Svensson L. (2006). Action and Interactive Research: Beyond Practice and Theory, Maastricht: Shaker Publishing.

Acker J. (1990). Hierarchies, jobs, bodies: a theory of gendered organizations, Gender and Society 4(2): 139-158. doi: https://doi.org/10.1177/089124390004002002.

Acker J. (2006). Inequality regimes: gender, class, and race in organizations, Gender \& Society 20(4): 441-464. doi: https://doi.org/10.1177/0891243206289499.

Acker J. (2009). From glass ceiling to inequality regimes, Sociologie Du Travail 51(2): 199-217. doi: https://doi.org/10.1016/j.soctra.2009.03.004.

Antonovsky A. (1990). A somewhat personal odyssey in studying the stress process, Stress Medicine 6(2): 71-80. doi: https://doi.org/10.1002/smi.2460060203.

Armstrong P. and Messing K. (2014). Taking gender into account in occupational health research: continuing tensions, Policy and Practice in Health and Safety 12(1): 3-16. doi: https://doi.org/10.1080/14774003.2014.11667794. 
Aronson J. and Neysmith S. M. (1996). "You're not just in there to do the work": depersonalizing policies and the exploitation of homecare workers' labor, Gender \& Society 10(1): 59-77. doi: https://doi.org/10.1177/089124396010001005.

Beer M. and Nohria N. (2000). Cracking the code of change, Harvard Business Review 78(3): 133-141.

Bolin M., \& Olofsdotter G. (2019). Bringing organizations back in: going from healthy work to healthy workplaces, Nordic Journal of Working Life Studies 9(4): 3-17. doi: https:// doi.org/10.18291/njwls.v9i4.117779.

Braun V. and Clarke V. (2006). Using thematic analysis in psychology, Qualitative Research in Psychology 3(2): 77-101. doi: https://doi.org/10.1191/1478088706qp063oa.

Brignall S. and Modell S. (2000). An institutional perspective on performance measurement and management in the 'new public sector', Management Accounting Research 11(3): 281-306. doi: https://doi.org/10.1006/mare.2000.0136.

Budgeon S. (2014). The dynamics of gender hegemony: femininities, masculinities and social change, Sociology 48(2): 317-334. doi: https://doi.org/10.1177/0038038513490358.

Clarke V. and Braun V. (2018). Using thematic analysis in counselling and psychotherapy research: a critical reflection, Counselling and Psychotherapy Research 18(2): 107-110. doi: https://doi.org/10.1002/capr.12165.

Däldehög A.-S. (ed). (2012). Genusmedvetet ledarskap: resan från ickefråga till tillväxtfråga (Leadership and Gender Awareness: A Journey from a Non Issue to a Question of Growth), Malmö: Liber.

England K. and Dyck I. (2011). Managing the body work of homecare, Sociology of Health and Illness 33(2): 206-219. doi: https://doi.org/10.1111/j.1467-9566.2010.01331.x.

EU-OSHA. (2019). Third Third European Survey of Enterprises on New and Emerging Risks (ESENER 3), In: EU-OSHA (ed) European Survey of Enterprises on New and Emerging Risks, EU Publications Office: European Agency for Safety and Health at Work, 15. https:/osha.europa.eu/en/publications.

Fine M. (2005). Individualization, risk and the body: sociology and care, Journal of Sociology 41(3): 247-266. doi: https://doi.org/10.1177/1440783305057077.

Frisby W., Maguire P. and Reid C. (2009). The 'f' word has everything to do with it: How feminist theories inform action research, Action Research 7(1): 13-29. doi: https://doi. org/10.1177/1476750308099595.

Gherardi S. (1994). The gender we think, the gender we do in our everyday organizational lives, Human Relations 47(6): 591-610. doi: https://doi.org/10.1177/001872679404700602.

Gherardi S. (2015). How the turn to practice may contribute to working life studies, Nordic Journal of Working Life Studies 5: 13-25. doi: https://doi.org/10.19154/njwls. v5i3a.4831.

Gustavsen B. (1992). Dialogue and Development: Theory of Communication, Action Research and the Restructuring of Working Life, Assen: Van Gorcum.

Hallgrímsdóttir H. K., Teghtsoonian K. and Brown D. (2008). Public policy, caring practices and gender in health care work, Canadian Journal of Public Health 99(2): 43-47. doi: https://doi.org/10.1007/bf03403804.

Heron J. and Reason P. (2001). The practice of co-operative inquiry: Research 'with' rather than 'on' people: 179-188. In: Reason P. and Bradbury H. (eds), Handbook of Action Research - Participative Inquiry \& Practice, London: SAGE.

Hirdman Y. (1988). Genussystemet: teoretiska funderingar kring kvinnors sociala underordning (The Gender Order: theoretical reflections on women's social subordination), Maktutredningen, Uppsala: Maktutredningen.

Hochschild A. R. (1990). Ideology and emotion management: A perspective and path for future research. In: Kemper T. D. (ed), Research Agendas in the Sociology of Emotions: 117-142. Albany: State University of New York Press. 
Hochschild A. R. (2003). The Managed Heart: Commercialization of Human Feeling: Twentieth Anniversary Edition with a New Afterword, Berkeley: University of California Press.

Husso M. and Hirvonen H. (2012). Gendered agency and emotions in the field of care work, Gender, Work \& Organization 19(1): 29-51. doi: https://doi.org/10.1111/j.14680432.2011.00565.x.

Hussein S. (2018). Job demand, control and unresolved stress within the emotional work of long-term care in England, International Journal of Care and Caring 2(1): 89-107. doi: https://doi.org/10.1332/239788218x15187915863909.

International Labour Organization. (2016). Women at Work: Trends 2016, Geneva: ILO.

Jenkins J. and Finneman T. (2018). Gender trouble in the workplace: applying Judith Butler's theory of performativity to news organizations, Feminist Media Studies 18(2): 157-172. doi: https://doi.org/10.1080/14680777.2017.1308412.

Johansson K. and Abrahamsson L. (2018). Gender-equal organizations as a prerequisite for workplace learning, The Learning Organization 25: 10-18. doi: https://doi.org/10.1108/ tlo-05-2017-0050.

Kamp A., Klemsdal L. and Gonäs L. (2013). Working in the public sector: introduction to the thematic issue, Nordic Journal of Working Life Studies 3(2): 1. doi: https://doi. org/10.19154/njwls.v3i2.2547.

Keisu B.-I., Öhman A. and Enberg B. (2016). What is a good workplace? Tracing the logics of NPM among managers and professionals in Swedish elderly care, Nordic Journal of Working Life Studies 6: 27-46. doi: https://doi.org/10.19154/njwls.v6i1.4884.

Kines P., Lappalainen J., Mikkelsen K. L., et al. (2011). Nordic Safety Climate Questionnaire (NOSACQ-50): a new tool for diagnosing occupational safety climate, International Journal of Industrial Ergonomics 41(6): 634-646. doi: https://doi.org/10.1016/j. ergon.2011.08.004.

Kmec J. A. and Gorman E. H. (2010). Gender and discretionary work effort: evidence from the United States and Britain, Work and Occupations 37(1): 3-36. doi: https://doi. org $/ 10.1177 / 0730888409352064$.

Korvajärvi P. (1998). Gendering Dynamics in White-collar Work Organizations, Tampere: Univ.

Kosny A. and MacEachen E. (2010). Gendered, invisible work in non-profit social service organizations: implications for worker health and safety, Gender, Work \& Organization 17(4): 359-380. doi: https://doi.org/10.1111/j.1468-0432.2009.00460.x.

Kvale S. and Brinkmann S. (2009). InterViews: Learning the Craft of Qualitative Research Interviewing, Los Angeles: Sage Publications.

Kvande E. (2003). Doing gender in organizations: theoretical possibilities and limitations, In Gunnarsson E., et al. Where Have All the Structures Gone? Doing Gender in Organizations. Examples from Finland, Norway and Sweden, Stockholm: Stockholm University.

Madsen A. A. (2018). Long-term sickness absence among professionals: investigating gender, socioeconomic position and care work, Nordic Journal of Working Life Studies 8(4): 45-69. doi: https://doi.org/10.18291/njwls.v8i4.111928.

Maguire P. (2006). Uneven ground: Feminisms and action research, In Reason P. and Bradbury H. (eds) Handbook of Action Research - Participative Inquiry \& Practice: 60-70. London: SAGE.

Martin-Matthews A. and Sims-Gould J. (2011). My home, your work, our relationship: elderly clients' experiences of homecare services. In: Benoit C. and Hallgrimsdóttir H. (eds) Valuing Care Work: Comparative Perspectives on Canada, Finland and Iceland: 107-124. Canada: University of Toronto Press. doi: https://doi.org/10.3138/9781442689992.

McCann L., Granter E., Hassard J., et al. (2015). "You can't do both-something will give": limitations of the targets culture in managing UK health care workforces, Human Resource Management 54(5): 773-791. doi: https://doi.org/10.1002/hrm.21701. 
Meagher G., Szebehely M. and Mears J. (2016). How institutions matter for job characteristics, quality and experiences: a comparison of home care work for older people in Australia and Sweden, Work, Employment and Society 30(5): 731-749. doi: https://doi. org $/ 10.1177 / 0950017015625601$.

Meldgaard Hansen A. (2016). Rehabilitative bodywork: cleaning up the dirty work of homecare, Sociology of Health and Illness 38(7): 1092-1105 doi: https://doi.org/10.1111/14679566.12435.

Messing K. (1998). One-eyed Science: Occupational Health and Women Workers 71, Philadelphia: Temple University Press.

Messing K. and de Grosbois S. (2001). Women workers confront one-eyed science: building alliances to improve women's occupational health, Women \& Health 33(1-2): 125-141. doi: https://doi.org/10.1300/j013v33n01 08 .

Nyström J. (2005). The definition of partnering as a Wittgenstein family-resemblance concept, Construction Management and Economics 23(5): 473-481. doi: https://doi. org/10.1080/01446190500040026.

Olofsdotter G. and Landén A. S. (2014). Gender as headline and subtext: problematizing the gender perspective in an occupational health project, Vulnerable Groups \& Inclusion 5(1): 23261. doi: https://doi.org/10.3402/vgi.v5.23261.

Pollitt C. and Dan S. (2011). The impacts of the New Public Management in Europe: A meta-analysis, Coordinating for Cohesion in the Public Sector of the Future.

Pousette A., Larsman P., Eklöf M., et al. (2017). The relationship between patient safety climate and occupational safety climate in healthcare - A multi-level investigation, Journal of Safety Research 61: 187-198. doi: https://doi.org/10.1016/j.jsr.2017.02.020.

Purkis M., Ceci C. and Bjornsdóttir K. (2011). Patching up the holes: analysing paid care work in homes, In Benoit C. and Hallgrimsdóttir H. (eds) Valuing Care Work: Comparative Perspectives on Canada, Finland and Iceland: 107-124. Canada: University of Toronto Press. doi: https://doi.org/10.3138/9781442689992.

Reason P. and Bradbury H. (2001). Handbook of Action Research: Participative Inquiry and Practice, London: SAGE.

Regnö K. (2013). Det osynliggjorda ledarskapet: kvinnliga chefer i majoritet (Women managers in majority), Dissertation, Stockholm: Royal Institute of Technology.

Reitz M. (2017). Analyzing and communicating action research data: practical approaches to conveying the quality and texture of experience, Action Research 15(4): 424-440. doi: https://doi.org/10.1177/1476750316660364.

Ringblom L. (2019). Utmanad ordning?: en studie av kön och jämställdhetsarbete i den svenska gruvindustrins arbetsorganizationer (Challenging the Gendered Order? A study of gender and gender equality work in the Swedish mining industry), Dissertation, Luleå: Luleå tekniska universitet.

Rosso C. B. and Saurin T. A. (2018). The joint use of resilience engineering and lean production for work system design: a study in healthcare, Applied Ergonomics 71: 45-56. doi: https://doi.org/10.1016/j.apergo.2018.04.004.

Strandell R. (2020). Care workers under pressure - a comparison of the work situation in Swedish home care 2005 and 2015, Health \& Social Care in the Community 28(1): 137-147. doi: https://doi.org/10.1111/hsc.12848.

Simpson R., Hughes J. and Slutskaya N. (2016). Embodying Dirty Work, In Gender, Class and Occupation, London: Palgrave Macmillan. doi: https://doi.org/10.1057/978-1-13743969-7 2.

Svensson L. et al. (2002). Interaktiv forskning - för utveckling av teori och praktik (Interactive research - for development of theory and practice) 7, Stockholm: Arbetslivsinstitutet. 
Szebehely M. (2005). Omsorgsvardag under skiftande organisatoriska villkor: en jämförande studie av den nordiska hemtjänsten, Tidsskrift for arbejdsliv 8(2): 49-66. doi: https://doi. org/10.7146/tfa.v8i1.108539.

Toulmin S. and Gustavsen B. (1996). Beyond Theory: Changing Organizations Through Participation, Philadelphia, Penn.: John Benjamins Publ.

Vänje, A. (2005). Knäcka koderna: praxis kring kön, industriell organisation och ledarskap (Breaking the Codes: Praxis concerning gender, industrial organization and leadership) Dissertation, Luleå: Luleå tekniska universitet.

Vänje A. (2013). Under The Magnyfying Glass: Gender perspective in work environment and work organisation, Knowledge Compilation 2013:1, Swedish Work Environment Authority, www.av.se.

West C. and Zimmerman D. (1987). Doing gender, Gender and Society 1(2): 125-151. doi: https://doi.org/10.1177/0891243287001002002. 